\title{
Roque Dalton, Lenin y la forma collage en Nuestra América
}

\author{
Roque Dalton, Lenin y and the collage form in Our America
}

Néstor Kohan*

Resumen: Se estudia la obra del salvadoreño Roque Dalton, principalmente su Un libro rojo para Lenin. Se analiza su formato de montaje-collage. Vinculando estilo y forma con contenido, se plantea como hipótesis que el collage es elegido para destacar la teoría (leninista y gramsciana) de la hegemonía. Se discute si en Dalton el collage asume un tono posmoderno o es un recurso vinculado al montaje de las vanguardias modernistas y su crítica del Mercado. Se comparan la hermenéutica sobre Lenin de Dalton con las de Victorio Codovilla, Rodolfo Ghioldi, Rodney Arismendi, Marta Harnecker, Atilio Borón y John Holloway.

Palabras clave: Collage, Hegemonía, Posmodernidad, Montaje, Crítica

Abstract: Here we study the work of the Salvadoran Roque Dalton, mainly his $A$ Red Book for Lenin. Its collage-edging format is analyzed. Linking style and form with content, it is proposed as a hypothesis that collage is chosen to highlight the theory (Leninist and Gramscian) of hegemony. It is discussed whether in Dalton collage assumes a postmodern tone or is a resource linked to the montage of the modernist avant-garde and their critique of the Market. The hermeneutics on Lenin by Dalton are compared with those of Victorio Codovilla, Rodolfo Ghioldi, Rodney Arismendi, Marta Harnecker, Atilio Borón and John Holloway.

Keywords: Collage, Hegemony, Postmodernity, Assembly, Criticism

Recibido: 27 mayo 2019 Aceptado: 2 julio 2019

\section{La historia como fuente de inspiración}

Hace más de medio siglo Roque Dalton [1935-1975] apeló a la memoria del viejo militante salvadoreño Miguel Mármol [1905-1993] para desenterrar y desempolvar una historia de rebeldía olvidada. Con ayuda de Mármol, Roque fue en busca del pasado para así iluminar el presente y cargarlo de energía (Dalton, 2007: 5). De esta manera pretendía conjurar los fantasmas de la realpolitik y el culto a la inmediatez de "lo posible". Ese fue el impulso principal que guió gran parte de su prosa política y su producción poética, marcadas a fuego por una mirada marxista herética y heterodoxa.

\footnotetext{
* Argentino. Doctor en Ciencias Sociales (Universidad de Buenos Aires). Investigador del Consejo Nacional de Investigaciones Científicas y Técnicas (CONICET) y del Instituto de Estudios de América Latina y el Caribe (IEALC). Profesor de la Facultad de Ciencias Sociales de la UBA. Correo electrónico: nestorkohan.academia@gmail.com
} 
A partir de esa inquietud espiritual que estructuró toda su escritura, elaboró un extenso libro, en forma de poema-collage, sobre Vladimir I. Lenin, un pensador demonizado, temido y, en la mayor parte de las ocasiones, desconocido y cuya principal obra (la revolución de octubre) modificó de raíz la historia de la humanidad. En este artículo nos centraremos precisamente en ese poema-collage que el poeta salvadoreño le dedica al pensador bolchevique, ya que allí se condensan y entrecruzan las principales coordenadas de su marxismo herético. Inspirados en la metodología dialéctica, iremos tras las pisadas de Dalton en busca del pasado para repensar nuestro presente.

\section{La relectura sobre el pensamiento bolchevique}

Después de las derrotas de los proyectos emancipadores del siglo XX, la lectura de los textos de Roque Dalton nos invita, nuevamente, a morder la fruta prohibida. "Es conveniente leer a Lenin", nos sugiere, "actividad tan poco común en extensos sectores de revolucionarios contemporáneos" (Dalton, 2001: 204).

Pero su consejo para las nuevas generaciones no queda detenido allí. Burlón, incisivo, irónico y mordaz, Dalton pone el dedo en la llaga. Luego de los relatos posmodernos más conservadores y de aquellas difusas ilusiones pseudo libertarias que pretendían "cambiar el mundo sin tomar el poder", Roque provoca a su público: "Cuando usted tenga el ejemplo de la primera revolución socialista hecha por la «vía pacífica», le ruego que me llame por teléfono. Si no me encuentra en casa, me deja un recado urgente con mi hijo menor, que para entonces ya sabrá mucho de problemas políticos" (Dalton, 2001: 205).

Partiendo de un enfoque completamente antagónico al que difundió a comienzos del siglo XXI el pensador autonomista irlandés John Holloway en su famoso ensayo dirigido explícitamente contra Lenin y en defensa de un programa que proponía transformar el mundo sin tomar el poder (Holloway, 2002: 28), Dalton focaliza su mirada crítica y su reflexión teórica precisamente en el problema fundamental del poder. Formula de este modo un desafio aún irresuelto por la mayoría de los procesos sociales y políticos contemporáneos de Nuestra América.

\section{La cocina doméstica de Un libro rojo para Lenin}

El impulso originario para la redacción de esta obra iconoclasta y provocadora responde a una invitación de un reconocido intelectual cubano, el poeta Roberto Fernández Retamar, director de Casa de las Américas. En 1970, al cumplirse el centenario del nacimiento de Lenin, Fernández Retamar convoca a varios poetas a escribir sobre él. De los muchos trabajos seleccionados, se eligen dos, uno de Roque Dalton y otro del intelectual haitiano René Depestre. Esa puntada inicial, redactada en La Habana, se fue entretejiendo posteriormente con múltiples materiales que Dalton va acumulando para su investigación sobre la obra del "principal teórico de la filosofía de la praxis" (Gramsci, 2000: 135). Aquella primera redacción acerca de Lenin se termina de completar recién tres años más tarde, en julio de 1973, en Hanoi, Vietnam del norte. El libro nace entonces en La Habana y concluye en Vietnam. Un itinerario geográfico que es también un recorrido político, índice expresivo de lo que Roque Dalton concibe, siguiendo explícitamente a Lukács, como "actualidad del leninismo" (Lukács, 2014: 15). El propio autor aclara al final del último poema de su libro, el "Ensayo de himno para la izquierda leninista", que su texto queda, adrede, inconcluso. Lo concibe como una obra abierta a los avatares de la revolución latinoamericana y a las nuevas lecturas que eventualmente se derivarían sobre Lenin en el futuro (su aclaración textual dice: "Poema inconcluso-mientras viva el autor"). 


\section{Una reflexión de madurez}

No obstante la notable juventud de su autor y al interior del arco de variación de su propia obra, las tesis, el formato y la gestación de Un libro rojo para Lenin forman parte de un texto de madurez. Una vez que culmina, en 1963, su primera investigación sociológica y política sobre la historia de El Salvador en forma de cuaderno monográfico publicado por Casa de las Américas (Dalton, 1963) que se prolonga y amplía en formato libro en El Salvador, Monografia (Dalton, [1965], 2010)- Roque comienza su tarea de maduración ideológica y radicalización política.

Intentando trazar un puente directo entre Farabundo Martí y la estrategia comunista insurgente (de inicial inspiración fidelista-guevarista) a escala continental, el poeta aprovecha su estadía en Praga, durante 1966, para husmear y reconstruir los testimonios orales de Miguel Mármol sobre la insurrección popular de 1932 dirigida por el Partido Comunista de El Salvador. Esos testimonios fueron recogidos en extensas entrevistas -registradas en forma manuscrita, sin grabador- a lo largo de tres semanas de mayo y junio de 1966. A partir de esa tarea rigurosa y obsesiva saldrá del horno el texto sobre la insurrección de 1932 y la masacre que la aplastó. De ese trabajo se publicaron fragmentos por primera vez en enero de 1971, en el número 48 de la revista cubana Pensamiento Crítico con el título "Miguel Mármol: El Salvador 1930-1932". Más tarde, ya muerto Dalton, se publicó el libro completo en forma póstuma. Fue en 1983. El libro llevaba por título Miguel Mármol. Los sucesos de 1932 en El Salvador y fue editado por Casa de las Américas (Dalton, 2007).

En una etapa posterior a aquel trabajo intelectual y ensayístico, Dalton se sumerge en las profundidades de los debates políticos abiertos por Regis Debray en la segunda mitad de los años '60. De allí surgirá el libro polémico Revolución en la revolución y la crítica de derecha donde el salvadoreño realiza su propio balance crítico sobre las absolutizaciones y unilateralidades de Debray, mientras, al mismo tiempo, ajusta cuentas con lo que denomina "la derecha del movimiento comunista latinoamericano" (Dalton, 1970: 11-12) que, por entonces, arremetía contra Debray como una vía indirecta, menos comprometida y con menor costo político, para atacar a Fidel Castro y al Che Guevara e impugnar a la revolución cubana, nave madre de gran parte de la insurgencia comunista y las rebeldías latinoamericanas, con excepción de la insurgencia colombiana que había surgido incluso antes de que Fidel y sus amigos atacaran el cuartel Moncada.

De modo que Un libro rojo para Lenin no es una obra juvenil, producto de un escritor demasiado entusiasmado y con excesiva voluntad, pero inexperto y recién llegado al mundo de la teoría social y la política emancipatoria. Por el contrario, en la trayectoria biográfica e ideológica de Roque Dalton constituye la coronación de una prolongada búsqueda política (siempre nutrida y entrecruzada con experimentaciones poéticas y militancia social) que comienza investigando la propia historia insurreccional de El Salvador en los años '30 y continúa más tarde con la polémica sobre la estrategia de la lucha rebelde en América Latina de los '60. Su lectura-diálogo-collage sobre Lenin conforma entonces el punto maduro de llegada de esas indagaciones previas y el paso necesario que Dalton emprende como plataforma ideológica de su incorporación activa a la lucha social y a la confrontación política en su propio país.

\section{La forma collage y la teoría de la hegemonía}

Al entablar una batalla ideológica de largo aliento contra todo un abanico de reformismos sociales, Roque logra conjugar un contenido revolucionario con una forma de expresión que violenta las cristalizaciones habituales y los géneros canónicos del discurso de izquierda. Su estilo disruptivo, su lectura heterodoxa y su retórica iconoclasta, no son ajenos al contenido que pretende compartir. En su construcción narrativa, no tiene sentido congelar una forma de expresión 
ni atarse a un solo género si se pretende transmitir un mensaje rebelde que rompa con los clichés y lugares comunes que impidieron durante décadas aprovechar y utilizar el inmenso arsenal teórico proporcionado por Lenin. Las rebeldías deberían estar, entonces, en ambos polos de la ecuación, en la forma y en el contenido, no sólo en este último. De este modo, Dalton lleva a la práctica en su escritura ensayística los recursos que ya había empleado en su poesía. La cultura rebelde se vuelve más eficaz y adquiere mayor capacidad de convencimiento cuando más irónica y mordaz.

Esa ironía, tan propia y característica de su escritura, le ayuda también a perderle el respeto a los géneros discursivos tradicionales. En ese sentido reaparece una y otra vez, en cada página de su escritura, una pregunta que no por tácita resulta menos operante: ¿por qué la polémica ideológica no puede ser poética? ¿por qué una obra poética debe renunciar a su proyección ideológico política? Al saltar por sobre los géneros, Dalton combina poemas, relatos, anécdotas y hasta documentos históricos con las instrucciones de Lenin para realizar un sabotaje, emplear una molotov, asaltar una comisaría, construir un ejército rebelde. En su conjunto, la obra constituye un inmenso collage en el que se integran materiales ensayísticos, biográficos, documentales, poéticos, musicales y pedagógicos.

Dentro de ese extenso y colorido collage, en su aproximación a Lenin y en la reconstrucción de su teoría (leninista y gramsciana) de la hegemonía, interviene una polifonía de voces que se entrecruzan con una notoria heterogeneidad de materiales y formatos. La decisión de apelar a tantos y tan heteróclitos materiales y la forma misma de montarlos en un collage elegido por el poeta salvadoreño para reconstruir el pensamiento de Lenin, no son ajenos al contenido ni a la materia que su obra pretende abordar.

En la biografía intelectual de Lenin, la teoría de la hegemonía se vuelve crucial y axial a partir de la publicación, en 1905, de su libro Dos tácticas de la socialdemocracia en la revolución democrática (Lenin, 1960: Tomo 9; Gruppi, 1977: 65). Tomando en cuenta dicha centralidad, como explica Raymond Williams: "A menudo el concepto de hegemonía en la práctica se asemeja a estas definiciones, sin embargo, es diferente en lo que se refiere a su negativa a igualar la conciencia con el sistema formal articulado que puede ser, y habitualmente es, abstraído como «ideología»" (Williams, 1980: 131).

En la lectura gramsciana de Raymond Williams, el concepto y la teoría de la hegemonía son superiores y mucho más abarcativos que la noción de "ideología" pues esta última tiende a asimilarse y a exponerse como "un sistema formal articulado". Esto es, como un círculo perfecto, sin fisuras, quiebres, amalgamas, fusiones, préstamos y resignificaciones, mientras que, en cambio, la teoría de la hegemonía integra bajo su arco multicolor y su estructura de sentimientos materiales diversos, demandas, reclamos, posturas e intereses diferentes que son articulados y a los cuales se les otorga un sentido unificador a partir de un proyecto político-cultural totalizante. Por lo tanto, resulta altamente probable que la forma collage (elegida por Dalton) se ajuste, precisamente, a ese contenido multicolor y vivencial que posee de por sí la categoría y la teoría de la hegemonía (pergeñada por Lenin y perfeccionada más tarde por Gramsci), a diferencia del carácter monocromático, racionalista, abstracto y unipolar que tendría, en la interpretación de Williams, la noción de "ideología"; por ejemplo, en el difundido artículo "Ideología y aparatos ideológicos del Estado" de Louis Althusser (Althusser, 1984: 120).

¿Será acaso posmoderno el collage, elegido por Roque Dalton y utilizado como eje de su libropoema, para retratar y reconstruir el pensamiento, la vida y la obra de Lenin? Sospechamos que no. $\mathrm{Su}$ propuesta de lectura-(re)escritura de Lenin posee ejes y contornos netamente definidos, habitualmente despreciados y vilipendiados por el llamado "pensamiento débil", término acuñado por el pensador italiano Gianni Vattimo, no por motivos filosóficos, sino a partir de un ímpetu polémico contra la izquierda revolucionaria italiana, como él mismo lo reconoce (Vattimo, 2009: 44). 
En primer lugar, la historia, especialmente la de América Latina, aunque también la de otras revoluciones antiimperialistas y anticapitalistas del mundo subdesarrollado. En segundo lugar, la hegemonía. En tercer lugar, el sujeto y, finalmente, en cuarto, pero no en último lugar, la revolución, proyecto totalizante, integrador y holista que permite articular y otorgar sentido a las demás partes. El collage de Dalton, repleto de retazos polifónicos, no tiene grandes fronteras en común con la fragmentación entrecortada de un videoclip posmoderno, donde las partes coexisten yuxtapuestas sin un sentido articulador que las ordene y les otorgue una dirección.

Recordemos con David Harvey que, en su teoría marxista de la historia y la cultura, Walter Benjamin trabajó con el collage-montaje "con el objeto de capturar las relaciones fragmentadas y superpuestas entre la economía, la política y la cultura, sin abandonar nunca la perspectiva de una totalidad de prácticas que constituyen el capitalismo". En la óptica de Harvey, el formato collage, del cual pretendieron apropiarse los pensadores y artistas posmodernos "no es un indicador adecuado de la diferencia entre la pintura modernista y la posmodernista" (Harvey, 1998: 69).

A diferencia de Harvey, para Fredric Jameson la forma collage está fuertemente vinculada en las experiencias culturales y audiovisuales del capitalismo avanzado y tardío a las "colecciones de fragmentos y la práctica fortuita de lo heterogéneo, lo fragmentario y lo aleatorio" Jameson, 1995: 61). Avanzando sobre esa primera aproximación, más tarde Jameson desarrolla sus ideas, complejiza su análisis y particulariza su tratamiento del collage remitiéndolo principalmente al predominio del video, sosteniendo que "En algún sentido, entonces, la palabra collage sirve aún para designar esta yuxtaposición de eso que uno se ve tentado de llamar materiales «naturales» (las secuencias filmadas directamente) y artificiales (las imágenes materiales precocinadas que han sido mezcladas por la propia máquina). Sería engañoso aplicar a esto la jerarquía ontológica del antiguo collage de la pintura" (Jameson, 2012: 135).

Por contraposición con estas apreciaciones de Jameson, en su reconstrucción de Los orígenes de la posmodernidad - que intenta elaborar el historiador británico Perry Anderson-, este último se esfuerza por vincular el collage con "la genuina modernidad internacional" dentro de una línea genealógica que él remite a Apollinaire, Marinetti, Jlébnikov, García Lorca, Attila Jószsef y Pablo Neruda (Anderson, 2016: 21).

Tomando en cuenta entonces estas diversas (y, por momentos, encontradas) evaluaciones del formato collage, creemos que en la obra de Roque Dalton el collage apela a lo heterogéneo y lo polifónico, pero desglosado del pastiche y la mera yuxtaposición aplanadora mercantil que anula diferencias específicas para homologar en un mismo registro aproximaciones (visuales, espaciales, poéticas o conceptuales) inconmensurables entre sí. De allí que muy probablemente, la particular entonación que adquiere la forma collage en Un libro rojo para Lenin se encuentra estrechamente vinculada, en lo que hace referencia a su contenido, a la amplitud multicolor de la teoría leninistagramsciana de la hegemonía (por sobre la uniformidad de la teoría althusseriana de la ideología) y, en lo que atañe a su linaje histórico, al recurso del montaje eisensteiniano, muchísimo más cercano a las vanguardias modernistas anticapitalistas que a la llamada "crisis de las grandes narrativas y los metarrelatos", de J.F.Lyotard, o a la esquizofrenia posestructuralista alabada por Deleuze y Guattari.

En su intento de articulación de diversas dimensiones como son la historia, la teoría leninista de la hegemonía, la noción de sujeto y el programa de revolución socialista, la composición narrativapoética de Roque Dalton reúne voces y materiales diferentes y heteróclitos, pero dentro de un mismo horizonte de sentido explícitamente crítico y rebelde que resulta sumamente lejano y distante de todo "pensamiento débil", la ya mencionada formulación programática del joven Gianni Vattimo (antes de que regresara a las filas del marxismo y el comunismo). Ese empleo del collage le permite dejar su libro abierto y expresamente inconcluso, a tono con el devenir del mismo proceso revolucionario y la propia historia del marxismo latinoamericano en los cuales este libro (y su autor) se insertan. 
La forma collage, la narrativa centrada en el montaje y el traspaso permanente de género en género, no son las únicas notas definitorias de esta singular y original escritura. Al mismo tiempo debemos registrar su humor, no como algo aleatorio o coyuntural, sino como un registro fundamental de toda la obra de Roque Dalton. El humor de Roque, por ejemplo, intercala, sin ningún tipo de advertencia al lector o la lectora en medio de una rigurosa explicación sobre el marxismo ruso, los populistas insurgentes y clandestinos partidarios de la lucha armada, de Plejanov y la formación política del joven Lenin, del pensador cubano Fernando Martínez Heredia (antiguo director de la revista heterodoxa Pensamiento Crítico), la frase de la famosa canción del cantante cubano Carlos Puebla: "pero entonces llegó el comandante y mandó a parar". Una irrupción sin aviso previo introducida con total desparpajo por Dalton en medio de un relato historiográfico que desconcierta a quien va leyendo y, como aquellas viejas técnicas teatrales que utilizaba Bertolt Brecht en su dramaturgia, despiertan al público y lo zarandean para que tome distancia del relato y así avance críticamente en la toma de conciencia. O también, aquella desopilante referencia a Gramsci y a su vínculo con la Internacional Comunista de su obra Un libro levemente odioso donde Roque Dalton, en lugar de escribir 575 páginas repletas de notas al pie y documentos de archivo, resume su explicación con frases pertenecientes a... jun bolero!: "¿Qué le dijo el movimiento comunista internacional a Gramsci? No tengo edad, no tengo edaaaad para amarte....” (Dalton, 2005: 57).

El humor de Roque se convierte así en una herramienta desacralizadora, un modo permanente de acercarse pedagógica y críticamente al marxismo y, en particular, a Lenin, evitando toda momificación, alivianando hasta corroer y disolver el peso del bronce que durante décadas aplastó su pensamiento siempre en ebullición. En medio de la risa y la ironía, la escritura de Roque Dalton invita a pensar en voz alta.

\section{La periodización acerca de Lenin, una aproximación histórica}

Después de investigar sobre la historia remota de El Salvador, de reconstruir la insurrección popular de 1932 y de ajustar cuentas con todo el affaire Debray, Dalton se vuelca a Lenin. No es casual. Los sectores más afines a la Unión Soviética invocaban su figura como vacuna frente a todos los "izquierdismos", principalmente el del Che Guevara y sus seguidores latinoamericanos.

¿Cuál es el Lenin que nos acerca Roque? Pues el Lenin más radical, partidario del trabajo clandestino, el arte de la insurrección, la revolución y la lucha por el poder. En esta elección suya advertimos una perspectiva político-ideológica inequívoca. El gran presupuesto de Dalton se asienta en una cosmovisión que concibe al marxismo como una teoría de la rebelión y no como una doctrina académica muerta asentada en una recopilación de citas "sagradas" tranquilizadoras. Según Roque Dalton "nos interesa muchísimo más el Lenin de la toma de Petrogrado y el Lenin que nos llega a través del Che Guevara y el general Giap, que el Lenin (genial, sin duda) de la NEP [Nueva Política Económica. Nota de N.K.] o el Lenin que nos llega a través del informe sobre los éxitos de la última cosecha de trigo en Ucrania" (Dalton, 2001:204).

La aproximación a Lenin está dada por la historia, la del propio Lenin y la de sus lectores y lectoras actuales, con problemas diversos a los de 1917 pero para quienes acudir al pensamiento del líder bolchevique puede resultar sumamente útil y provocador. De allí que Dalton, sucinto y económico, defina de la siguiente manera: "El leninismo es un complejo resultante de la historia, no una impenetrable bola de acero" (Dalton, 2001: 200).

En esa aproximación a Lenin, que no por ser sugerente y en perspectiva deja de ser objetiva, no por tomar partido deja de ser rigurosa y estricta, no por elegir un perfil de abordaje deja de tomar en cuenta los documentos y la investigación historiográfica, Roque Dalton aclara a cada paso desde donde habla y contra quien escribe. Sus interlocutores polémicos están abiertamente mentados en el poema "Contra quien es este libro". Además de oportunistas, allí los clasifica -una vez más, 
irónicamente- como "full backs de la burguesía", aquellos que acusan de "blanquismo" a la naturaleza y a la historia o creen que la gran obra de Marx consiste en haber prevenido a la clase obrera contra el revolucionarismo excesivo (Dalton, 2001: 175-176).

$\mathrm{Si}$ resulta claro con quien es la polémica, también son nítidas las acusaciones que Dalton pretende contestar. Están enumeradas en el poema titulado "En la polémica nos dicen" (Dalton, 2001: 119). Esto es: anarquistas, bandoleros, extremistas, terroristas, antisociales...

Si hubiera que resumir en una sola categoría de la historia política del movimiento socialista todos esos insultos, ese concepto sería el de "blanquismo", referencia despectiva que remite al líder conspirador francés del siglo XIX, Louis Auguste Blanqui [1805-1881]. Esa fue la principal categoría a la que apeló Eduard Bernstein, cabeza intelectual del reformismo de la Segunda Internacional, contra todo el marxismo revolucionario (Bernstein, [1899] 1982: 133-134, 217).

Dalton se propone rescatar a Lenin (y a todo el marxismo rebelde de América latina) de las acusaciones de "blanquismo", pero también de otras que suelen acompañarlo: "aventurerismo", "putshchismo", "romanticismo", "jacobinismo" y "babuvismo" (referencia despectiva que remite a Graco Babeuf [1760-1797]). Todos estos epítetos fueron acuñados por la socialdemocracia de fines del siglo XIX y empleados por el estalinismo durante la década de 1960 para impugnar el movimiento de rebeldía nacido al calor de la revolución cubana.

Toda la polémica ideológica entablada por Roque Dalton se propone defender la legitimidad política del pensamiento revolucionario latinoamericano y hacer jugar a Lenin en esa disputa. El Lenin que nos aproxima Dalton, a través de discursos históricos, artículos o testimonios de investigadores, no está solo en este poema-collage. Lo acompañan el Che Guevara, Fidel Castro, el general Giap, Ho Chi Minh, Antonio Gramsci, György Lukács y León Trotsky.

\section{Dalton sobre Lenin, Trotsky y Blanqui}

En Un libro rojo para Lenin aparece en relieve la figura polémica de León Trotsky. El autor extracta y reproduce fragmentos de su célebre Historia de la revolución rusa, aquella voluminosa obra en la cual el fundador del Ejército bolchevique subraya las fuertes deudas que el marxismo radical mantiene con Blanqui, sin obviar las diferencias recíprocas.

Aunque el objeto de debate predilecto de Roque Dalton es, principalmente, la ortodoxia de los soviéticos y el estalinismo -por ejemplo, de Victorio Codovilla [1894-1970] y Rodolfo Ghioldi [18971985], dos dirigentes del PC argentino a quienes cuestiona con nombre y apellido en su otro libro Revolución en la revolución y la crítica de derecha (Dalton, 1970: 24-25)-, el radio de alcance de sus polémicas llega más allá de ese espacio restringido. Su crítica es extensible a otras vertientes del estalinismo latinoamericano.

¿Qué adopta Dalton de Trotsky? Lo que más le llama la atención en su narración histórica y en su reflexión teórica es el abordaje del problema del sujeto colectivo y el papel activo de los revolucionarios de la historia. Un antiguo problema teórico que ya había sido tratado por Georgi Plejanov [1856-1918] en su obra El papel del individuo en la historia [1898], sobre el cual vuelve Trotsky a la hora de analizar el papel de Lenin en su regreso a San Petersburgo, de abril de 1917, y en la revolución de octubre del mismo año.

En ese sentido, en el cual Trotsky se aleja (por lo menos a nivel historiográfico) del objetivismo tradicional del marxismo ortodoxo, mientras recupera las corrientes más radicales de revolucionarios inclusive anteriores o contemporáneos a Karl Marx, a Roque Dalton le llamó poderosamente la atención la forma en que el creador del Ejército Rojo bolchevique define al "blanquismo". Según el autor de Historia de la revolución rusa, reproducido por Dalton, por blanquismo debe entenderse no una desviación elitista, militarista o conspiradora del socialismo pergeñada por L. A. Blanqui sino, por el contrario, la esencia revolucionaria del pensamiento marxista. No es casual 
que Dalton se haya detenido en este párrafo de Trotsky, ya que en América Latina las corrientes políticamente más moderadas emplearon el término de "blanquismo" para descalificar a la revolución cubana y a sus simpatizantes a escala continental.

\section{Lenin desde el marxismo latinoamericano}

A lo largo de toda su hermenéutica iconoclasta y provocadora, por el contenido y la forma, el poeta salvadoreño se propone, nada menos, que traducir a Lenin a nuestra lengua política, nuestra idiosincrasia y nuestra historia, insertándolo en lo más rebelde y radical de las tradiciones revolucionarias latinoamericanas. No es aleatorio que en su reconstrucción apele a otras experiencias de revoluciones en países del Tercer Mundo como la atrasada Rusia, la periférica China o las revoluciones en pequeños países como Vietnam, Cuba, El Salvador, que resultaron ser altamente significativas y atractivas para el movimiento de rebeldía juvenil a escala mundial... El Lenin de Dalton se viste de moreno, de indígena, de campesina, de cristiano revolucionario, de habitante de población, villa miseria, cantegril y favela, además de obrero industrial, moderno y urbano. La suya es una lectura ampliada de Lenin, pensada para que mueva las aguas y las estanterías ya no exclusivamente en las grandes metrópolis del occidente europeonorteamericano, sino, principalmente, en el Tercer Mundo (hoy más conocido como "el Sur Global"), única manera de mantenerlo vivo y al alcance de la mano en las rebeliones más próximas de América latina.

Esa perspectiva permite comprender la dedicatoria del libro que, aunque está cargada de afecto y admiración, implica también una definición política, ya que Roque Dalton lo dedica " $A$ Fidel Castro, primer leninista latinoamericano, en el XX aniversario del asalto al Cuartel Moncada, inicio de la actualidad de la revolución en nuestro continente" [subrayado de R.D.] (Dalton, 2001: 10). Esa dedicatoria a Fidel Castro retoma puntualmente la tesis central del libro de Lukács sobre Lenin (Lukács, [1924] (2014): $14-40)$.

\section{Lectura sobre las lecturas, espejo sobre los espejos}

La obra de Roque Dalton tiene como objetivo fundamental pensar y repensar qué significa el leninismo para y desde América latina. Su reflexión merece ser balanceada y contrastada con otras aproximaciones análogas realizadas en este continente.

En primer lugar, con el "leninismo" construido por Victorio Codovilla [1894-1970] y Rodolfo Ghioldi [1897-1985], dos de los principales exponentes argentinos de la corriente latinoamericana afín a la Unión Soviética. Estos dos dirigentes comenzaron a ser hegemónicos dentro del Partido Comunista argentino (PCA) a partir de 1928, cuando ya hacía diez años que éste se había fundado (Kohan, 2000: 117-119). Alineados en forma férrea con la vertiente de Stalin en el Partido Comunista de la Unión Soviética (PCUS), Codovilla y Ghioldi pasaron a dirigir, de hecho, la sección sudamericana de la Internacional Comunista (IC). Desde allí combatieron duramente las posiciones de los delegados de José Carlos Mariátegui [1894-1930] (Secretariado Sudamericano de la Internacional Comunista [1929] (2019): 326-331 y 337), difundieron sospechas políticas sobre Julio Antonio Mella [1903-1929] y criticaron en forma desmedida a todo el movimiento político-cultural de la Reforma Universitaria nacido en Córdoba, Argentina, en junio de 1918 (Secretariado Sudamericano de la Internacional Comunista [1929] (2019): 141-147).

Cuarenta años más tarde, durante los años '60, Codovilla y Ghioldi volvieron a repetir la misma actitud de aquellos años '20, cuestionando nuevamente la herencia de Mariátegui y polemizando con la nueva herejía que emanaba entonces de las barbas selváticas de Cuba (Codovilla, V. (1964)). Desde ese ángulo, construyeron una pretendida "ortodoxia" leninista desde la cual 
persiguieron a cuanto "heterodoxo" se pusiera por delante (Ghioldi, R. (1967)). Lenin, en este registro estalinista rudimentario, se convierte en un recetario de fórmulas rígidas, propiciadoras del "frente democrático", la alianza de clases con la llamada "burguesía nacional" y la separación de la revolución en rígidas etapas. Además, desde los años '50 en adelante, el "leninismo" de Codovilla y Ghioldi se fue convirtiendo en sinónimo de "tránsito pacífico" al socialismo y oposición a toda confrontación irregular (a pesar de que Ghioldi había participado en 1935 en la insurrección fallida encabezada por Luis Carlos Prestes [1898-1990] en Brasil).

Todo el emprendimiento de Roque Dalton en Un libro rojo para Lenin constituye una crítica frontal y radical, punto por punto, parte por parte, de esta versión de "leninismo" divulgada y custodiada en tierras latinoamericanas por el italiano Victorio Codovilla y el argentino Rodolfo Ghioldi.

En segundo lugar, en América Latina el líder del Partido Comunista uruguayo (PCU) Rodney Arismendi [1913-1989] elaboró una versión bastante más refinada y meditada de "leninismo" (Arismendi, 1970 y 1984). La suya fue una lectura más sutilmente elaborada y no tan esquemática como la de Codovilla y Ghioldi -lo que le permitió cierto diálogo con la vertiente guevarista, como el mismo Dalton reconoce en su otro libro Revolución en la revolución y la crítica de derecha, al punto que Arismendi es el único dirigente de un partido comunista tradicional en participar de la OLAS [Organización Latinoamericana de Solidaridad] reunida en La Habana en 1967-aunque compartiera, en términos generales, el mismo paradigma político que los dos dirigentes de Argentina. (Puede consultarse el documento fundacional y la proclamación final de la OLAS en Estrada, Ulises y Suarez Salazar, Luis (2006): 403-405 y Löwy, Michael [1980] (2007): 321-333).

En tercer lugar, y ya bajo la estrella de la revolución cubana, la pedagoga chilena Marta Harnecker intentará una nueva aproximación a Lenin desde América Latina. Lo hará desde la óptica política y epistemológica althusseriana, ya que Harnecker fue, durante años, una de las principales alumnas y difusoras del pensamiento de Louis Althusser en idioma castellano y en tierras latinoamericanas. Ese intento de lectura se cristalizará en la obra La revolución social (Lenin y América Latina) (1986), de algún modo complementaria de otras suyas como Táctica y estrategia (1987); Enemigos, aliados y frente político (1987), y la más famosa de todas, Los conceptos elementales del materialismo bistórico [1969] (1971), publicada con presentación del mismo Louis Althusser y editada más de 50 veces. Un auténtico best seller latinoamericano.

La obra pedagógica de Harnecker, mucho más apegada a Lenin que los anteriores intentos etapistas de Codovilla, Ghioldi o, incluso, el más refinado de Arismendi, tiene un grado de sistematicidad bastante mayor que la de Roque Dalton. Sin embargo, por momentos los esquemas construidos por M. Harnecker rinden un tributo desmedido a situaciones de hecho, coyunturales. Por eso sus libros teóricos van de algún modo "acompañando" los procesos políticos latinoamericanos. Así, perspectivas políticas determinadas se convierten, en varios de sus libros, por momentos, en "modelos" casi universales: lucha guerrillera -como en Cuba- en los '60; lucha institucional y poder local -como en Brasil y Uruguay- en los '80 y '90; procesos de cambios radicales a través del ejército -como en Venezuela- desde el 2000. Y el modelo (de origen yugoslavo) de "autogestión", con posterioridad al proceso bolivariano de las comunas en Venezuela.

El libro de Dalton, sin duda menos sistemático y con menor cantidad de referencias y citas bibliográficas de los escritos de Lenin que estos manuales de Harnecker, posee, sin embargo, una mayor aproximación al núcleo fundamental del Lenin en tanto pensador de la revolución anticapitalista. La menor sistematicidad y menor cantidad de citas textuales, es compensada con una mayor frescura (no sólo por la forma collage) y con una mayor amplitud de perspectiva de pensamiento político.

En cuarto lugar, debemos recordar la operación de desmontaje de la herencia rebelde de Lenin que, desde comienzos de los años '80 pretendieron realizar los argentinos (por entonces exiliados) Juan Carlos Portantiero [1934-2007] (Portantiero, 2000: 32), Ernesto Laclau [1935-2014] (Laclau y Mouffe, 
1987: 76) y José Aricó [1931-1991] (Aricó, 1985: 14-15), entre otros. Toda su relectura de Gramsci en clave explícita y expresamente antileninista, constituye un sutil intento de fundamentar su pasaje y conversión de antiguas posiciones radicalizadas a posiciones moderadas (esta referencia vale para Portantiero y Aricó, ambos de origen comunista, no así para Laclau, quien nunca militó en la izquierda radical sino en la denominada "izquierda nacional", apoyabrazos progresista del populismo, tan distinto y tan distante del peronismo revolucionario de John William Cooke, amigo personal del Che Guevara).

Concretamente, el ataque a Lenin (acusado reiteradamente de "blanquista", "jacobino" y "estatalista") y la manipulación de Gramsci (resignificado, en Portantiero y Aricó, desde el eurocomunismo italiano y sus derivas socialdemócratas posteriores; así como, en el caso de Laclau, por el posmodernismo deconstruccionista francés, entremezclado con los juegos de lenguaje del último Ludwig Wittgenstein y el significante vacío de Jacques Lacan) cumplen en los ensayos de Portantiero, Aricó y Laclau el atajo directo para legitimar con bombos y platillos su ingreso alegre a la socialdemocracia, tras la renuncia a toda perspectiva anticapitalista y antimperialista. No podían realizar ese tránsito sin ajustar cuentas con la obra de Lenin, núcleo de fuego...incluso para los ensayistas más refinados, eruditos y hábiles.

El libro de Roque Dalton, pensado originariamente en los años de oro y expansión ideológica de la revolución cubana para discutir con el reformismo y las moderaciones de "la derecha del movimiento comunista latinoamericano", está repleto de argumentos que, incluso, décadas después y de reflujo de la izquierda mediante, les quedan holgados y sobreabundantes a las elaboraciones tímidamente reformistas de estos tres pensadores de la socialdemocracia.

En quinto lugar, no podemos obviar el intento más cercano en el tiempo de John Holloway y sus seguidores latinoamericanos por responsabilizar a Lenin de todos los males y vicios habidos y por haber, en el pasado, en el presente y en el futuro: "sustitucionismo", "verticalismo", "autoritarismo", "estatalismo", etc (Holloway, 2002). La "novedad" que inaugura el planteo de Holloway consiste en que realiza el ataque contra las posiciones radicales que se derivan de Lenin con puntos de vista reformistas, pero..., a diferencia de los antiguos simpatizantes afines a la Unión Soviética o de los socialdemócratas aggiornados y posmodernos, él lo hace con lenguaje pretendidamente libertario y de izquierda. Esa jerga nebulosa y seductora encubre en Holloway un reformismo poco disimulado y una impotencia política mal digerida o no elaborada (extraída de un esquema demasiado abstracto y esquemático de la experiencia neozapatista -nunca autorizada como su "teoría oficial", dicho sea de paso, por el propio EZLN mexicano-, caprichosamente despojada de toda perspectiva histórica o de toda referencia a las luchas campesinas del zapatismo de principios del siglo XX, que poco o nada interesan a Holloway). Toda la crítica de Roque Dalton golpea contra este tipo de planteos equívocos al estilo de Holloway (o de sus seguidores autonomistas), aunque por vía indirecta, ya que al redactar su polémico collage Roque Dalton pretendía cuestionar posiciones más ingenuas, menos sutiles y, si se quiere, más transparentes y diáfanas, aunque cuestionables, en sus objetivos políticos.

Finalmente, a la hora de parangonar y hacer un balance de la lectura de Roque Dalton comparándola con otras hermenéuticas latinoamericanas -a favor o en contra- sobre Lenin, nos topamos con el análisis del pensador argentino Atilio Borón (Borón, 2004). Este autor, de identidad política comunista en sus últimos años, acude al ¿Qué hacer?, para analizarlo, interrogarlo y reivindicarlo desde la América Latina contemporánea.

No es casual que, como Roque Dalton, Borón llegue a una conclusión análoga cuando señala a Fidel Castro como uno de los grandes dirigentes políticos que han comprendido a fondo a Lenin. Particularmente, hace referencia a la importancia atribuida por Lenin al debate teórico y a la conciencia y lo homologa con el lugar privilegiado que ocupaba la "batalla de las ideas" en el pensamiento de Fidel Castro en sus escritos de los últimos años antes de fallecer. 
Después de la rebelión popular argentina de diciembre de 2001, Borón analiza las tesis leninistas del ¿Qué hacer? y las emplea para polemizar con el "espontaneísmo", sobre todo de John Holloway, quien, de hecho, clasifica a Lenin como un vulgar "estatista autoritario". También polemiza con la noción deshilachada y difusa de "multitud" de Toni Negri, quien cree, erróneamente, que toda organización partidaria de las clases subalternas, termina subordinando los movimientos sociales bajo el reinado despótico del Estado. Crítico de ambas interpretaciones -la de Holloway y la de Negri-, el planteo comunista de Borón sostiene que gran parte de las revueltas populares de comienzos del siglo XXI han sido "vigorosas pero ineficaces", ya que no lograron, como en el caso argentino, instaurar un gobierno radicalmente distinto a los anteriores ni construir un sujeto político, anticapitalista y antiimperialista, perdurable en el tiempo (Boron, 2004). En este tipo de lecturas, el leninismo de Borón mantiene una fuerte deuda con las hipótesis históricas del pensador uruguayo Rodney Arismendi, a quien cita explícitamente en su ensayo, aunque, en el caso del politólogo argentino, esas conclusiones a favor de un comunismo democrático, estén completamente despojadas de todo vínculo con el estalinismo. Junto con Arismendi, los planteos de Borón en su hermenéutica de Lenin se acercan también a las reflexiones del italiano Galvano Della Volpe, en sus polémicas ya clásicas con el social-liberalismo de Norberto Bobbio (Della Volpe, 1963).

De la misma forma que el salvadoreño Roque Dalton, en su trabajo sobre Lenin el ensayista comunista Borón cuestiona "las monumentales estupideces pergeñadas por los ideólogos soviéticos y sus principales divulgadores". Si bien Borón y Dalton se esfuerzan por delimitar la reflexión de Lenin de aquello en lo que derivó posteriormente en estalinismo, depositan sus miradas en aristas algo disímiles. Por ejemplo, mientras Borón critica -siguiendo a Marcel Liebman- lo que caracteriza como una "actitud sumamente sectaria" de Lenin durante el período 1908-1912, Dalton defiende aquellos escritos de Lenin donde emerge su lado más radical y combativo.

\section{La crítica irónica más allá de las fuerzas del Mercado}

Las reflexiones de Un libro rojo para Lenin poseen notorios vasos comunicantes con todas estas otras iniciativas intelectuales y hermenéuticas latinoamericanas, pero, en el caso del salvadoreño, poseen además y, por sobre ellas, una densidad propia y específica.

La propuesta política de Roque Dalton, atravesada por los sueños ardientes y postergados de la década de 1960 y marcada en las entrañas por los años heroicos de la revolución cubana, mantiene, sin embargo, una sorprendente actualidad. Si bien es innegable que el "espíritu de época" del cual se nutre y alimenta Dalton en su obra no es precisamente el nuestro (mucho más sombrío, sin duda), también es verdad que su libro-collage golpea la mesa reinstalando en la agenda de debates contemporáneos una serie de problemas pendientes y preguntas que permanecen todavía irresueltos y que se resumen en el siguiente interrogante:

¿Cómo pensar la crítica cultural (y política) más allá del Mercado? Reflexionando sobre esas interrogaciones, Terry Eagleton escribía: "Suspendido precariamente entre la clase culta y las fuerzas del Mercado, el crítico representa el último intento bistórico de suturar estos dos reinos" (Eagleton, 1999: 54).

Roque Dalton es un fiel exponente de esa actitud y teoría crítica que no se deja fagocitar por ninguno de esos dos universos que lo amenazan a cada costado (precisamente por eso su escritura collage se encuentra mucho más próxima al montaje de las vanguardias modernistas anticapitalistas, que, al pastiche ecléctico de la sensibilidad posmoderna, de hecho simpatizante $o$, al menos, nunca refractaria ante la aplanadora del mundo mercantil). En ese sentido, resulta notorio que para no dejarse deglutir por semejantes dragones eligiera como escudo (y objeto de estudio), precisamente a una figura irrecuperable e incómoda frente a toda dominación capitalista como... Lenin. No podía haber elegido otro antídoto mejor. 
La poesía coloquial y la prosa irónica de Dalton, entrecruzadas, articuladas y sobreimpresas en un montaje-collage con los materiales heteróclitos que elige de y sobre Lenin, deben ser (re)leídos a contrapelo de la historia de los capitalistas vencedores y las burocracias derrotadas que hablaron en su nombre. Dicho montaje-collage vuelve a colocar en el centro de las discusiones los proyectos y las estrategias rebeldes del siglo XXI tanto el desafío de la crítica cultural -que no se subordina al Mercado- como el problema político del poder, ambos abandonados, eludidos o incluso re-negados durante un cuarto de siglo de hegemonía neoliberal, en la política y en la cultura.

Roque Dalton provoca, molesta, incomoda. Aún hoy. Se burla de los vencedores. Desprecia a los acomodaticios. Se mofa de las burocracias corrompidas y conversas (que reniegan de su propia identidad histórica). Se toma en solfa la adustez de los discursos cristalizados y las narrativas ensayísticas que citan mucho para no decir nada. Navegando contra la corriente en el río turbulento de la crítica cultural, su escritura también sirve para pensar las derrotas de las revoluciones latinoamericanas desde la izquierda, sin hacer tabla rasa con el pasado, negándose a olvidar los heroísmos anónimos y la militancia desaparecida a sangre y fuego. Su risa no es cínica, sino crítica. Su collage mantiene la ironía pesimista del entendimiento, pero está lleno de alegría, de optimismo y de esperanza.

\section{Bibliografía}

Althusser, Louis [1970] (1984): La filosofía como arma de la revolución. México, Siglo XXI.

Anderson, Perry (2016): Los orígenes de la posmodernidad. Madrid, Akal.

Aricó, José (1985) "Prólogo" a Jaime Labastida (comp.) [1980] (1985), Hegemonía y alternativas políticas en América Latina. México, Siglo XXI.

Arismendi, Rodney (1970): Lenin, la revolución y América latina. Montevideo, Pueblos Unidos.

Arismendi, Rodney (1984): Vigencia del marxismo-leninismo. México, Grijalbo.

Bernstein, Eduard [1899] (1982): Las premisas del socialismo y las tareas de la socialdemocracia. México, Siglo XXI.

Borón, Atilio (2004), "Estudio introductorio al «¿Qué hacer?» de Lenin". En Vladimir. I. Lenin (2004): ¿Qué hacer? Problemas candentes de nuestro movimiento. Buenos Aires, Editorial Luxemburg.

Codovilla, Victorio (1964): "La penetración de las ideas del marxismo-leninismo en América latina". En Revista Internacional VII, No8. Praga [Checoslovaquia].

Dalton, Roque (1963): El Salvador. La Habana, Casa de las Américas. Dalton, Roque [1965] (2010), El Salvador. Monografía. México, Ocean Sur.

Dalton, Roque (1970): ¿Revolución en la revolución? y la crítica de derecha. La Habana, Casa de las Américas.

Dalton, Roque [1971] (2007): Miguel Mármol. Los sucesos de 1932 en El Salvador. Bogotá, Ocean Sur.

Dalton, Roque [1970-1973] (2001): Un libro rojo para Lenin. San Salvador, Universidad Centroamericana-UCA editores.

Dalton, Roque (2005): Un libro levemente odioso. San Salvador, Universidad Centroamericana-UCA editores.

Della Volpe, Galvano (1963): Roussean y Marx y otros ensayos de crítica materialista. Buenos. Aires, Platina. Eagleton, Terry (1999): La función de la crítica. Barcelona, Paidos.

Gramsci, Antonio (2000), Cuadernos de la cárcel [Edición crítica]. México, Editorial ERA. Tomo I al VI. Estrada, Ulises y Suarez Salazar, Luis (2006): Rebelión Tricontinental. Las voces de los condenados de la tierra de Africa, Asia y América Latina. New York, Ocean Sur.

Ghioldi, Rodolfo (1967): No puede baber una "revolución en la revolución". Buenos Aires, Anteo.

Gruppi, Luciano (1977): Elpensamiento de Lenin. México, Grijalbo. 
Harnecker, Marta [1969] (1971): Los conceptos elementales del materialismo histórico. Buenos Aires, Siglo XXI. Harnecker, Marta (1986): La revolución social (Lenin y América latina). Buenos Aires, Contrapunto. Harnecker, Marta (1987): Táctica y estrategia. Buenos Aires, Contrapunto. Harnecker, Marta (1987): Enemigos, aliados y frente politico. Buenos Aires, Contrapunto.

Harvey, David (1998): La condición de la posmodernidad. Investigación sobre los orígenes del cambio cultural. Buenos Aires, Amorrortu.

Holloway, John (2002): Cambiar el mundo sin tomar el poder. Buenos Aires, Herramienta.

Jameson, Fredric (1995): El posmodernismo o la lógica cultural del capitalismo avanzado. Buenos Aires, Paidos.

Jameson, Fredric (2012): "La imagen". En Posmodernismo. La lógica cultural del capitalismo avanzado. Buenos Aires, La Marca Editora. Tomo I.

Jameson, Fredric (2014): Las ideologias de la teoría. Buenos Aires, Eterna Cadencia editora.

Kohan, Néstor (2000): De Ingenieros al Che. Ensayos sobre el marxismo argentino y latinoamericano. Buenos Aires, Biblos.

Laclau, Ernesto y Mouffe, Chantal (1987): Hegemonia y estrategia socialista. Hacia una radicalización de la democracia. Madrid, Siglo XXI.

Lenin, Vladimir I. (1960): Obras completas. Buenos Aires, Cartago. Tomo 9. Löwy, Michael [1980] (2007): El marxismo en América latina (De 1909 a nuestros días). Santiago de Chile, LOM.

Lukács, György [1924] (2014): Lenin: La coherencia de su pensamiento. China, Ocean Press.

Portantiero, Juan Carlos (2000): El tiempo de la política. Construcción de mayorias en la evolución de la democracia argentina 1983-2000. Buenos Aires, Temas Grupo Editorial S.R.L.

Secretariado Sudamericano de la Internacional Comunista [1929] (2019): El movimiento revolucionario latinoamericano. Versiones de la Primera Conferencia Comunista latinoamericana del 1 al 12 de junio de 1929. Buenos Aires, La Correspondencia Sudamericana [El grueso volumen — durante muchos años inhallable o en poder de exclusivos coleccionistas - hoy se puede leer y descargar íntegra y gratuitamente del siguiente link: $\underline{\mathrm{http}} / / /$ cipec.nuevaradio.org/?p=92 Lo hemos digitalizado del archivo personal del historiador marxista Rodolfo Puiggrós].

Vattimo, Gianni (2009): Ecce comu. Cómo se llega a ser lo que se era. Buenos Aires, Paidós.

Williams, Raymond [1977] (1980): Marxismo y literatura. Barcelona, Península. 